Tetrahedron Letters

journal homepage: www.elsevier.com

\title{
Nucleophilic Additions to Polarized Vinylarenes
}

\author{
Krishna Kumar Gnanasekaran, Junghak Yoon and Richard A. Bunce* \\ Department of Chemistry, Oklahoma State University, Stillwater, OK 74078-3071, USA
}

\section{ARTICLE INFO}

\section{Article history:}

Received

Received in revised form

Accepted

Available online

Keywords:

Nucleophilic addition

Polarized vinylarenes

Hydroamination

Reaction optimization

Steric effects

\section{ABSTRACT}

\begin{abstract}
The addition of nucleophiles to the terminal double bond carbon of a styrene incorporating an electron-withdrawing group at the ortho or para position has been studied. The conditions for this transformation have been optimized and structural modifications to the substrate have been explored. The structural changes included variation of the activating group on the aromatic ring and positioning substituents on the side chain double bond. The study revealed that nitro substitution gave the best results for addition of carbon and nitrogen nucleophiles. Cyanosubstituted systems added carbon nucleophiles, but underwent polymerization or degradation with nitrogen nucleophiles. Ethoxycarbonyl-bearing substrates reacted primarily at the ester carbonyl. The reaction generally proceeded well with methyl on the $\alpha$ carbon of the double bond, but was slowed by methyl at the $\beta$ position. The yields varied from $50-97 \%$ for 22 examples.
\end{abstract}

2009 Elsevier Ltd. All rights reserved.
Carbon-carbon and carbon-nitrogen bond formations by Michael ${ }^{1,2}$ and $\mathrm{S}_{\mathrm{N}} \mathrm{Ar}^{3,4}$ reactions have been important synthetic tools for many years. The Michael reaction involves the addition of a nucleophile to a double bond polarized by conjugation with an electron-withdrawing group and is facilitated by stabilization of the intermediate anion $\alpha$ to the polarizing group. The $S_{N} A r$ typically involves displacement of an aryl-bound halide by a nucleophile via an addition-elimination mechanism, which is possible when a strong electron-withdrawing group is situated ortho or para to the halide. This process is assisted by delocalization of the negative charge toward the activating group on the aromatic ring in a Meisenheimer complex. In the current reaction, we have explored the addition of nucleophiles to several vinylarenes (styrenes) bearing strong electron-withdrawing groups on the aromatic ring. The effect is to polarize the double bond such that addition of a nucleophile can take place at the side chain double bond terminus. The resulting anion is then stabilized in a Meisenheimer-like complex by delocalization into the aromatic ring.

To date, only one report ${ }^{5}$ has appeared describing nucleophilic additions to electron deficient styrene double bonds. In this account, the addition of malonate to 2- and 4-nitrostyrene using sodium ethoxide in alcohol (equilibrating conditions) gave moderate yields ( $72 \%$ and $45 \%$, respectively) of the single addition products, and in the latter case, a substantial quantity (34\%) of the double addition product. We recently utilized this reaction to prepare $\mathbf{1 a}$, which was converted, using iron in acetic acid, to the ring-fused synthetic building block ( \pm )-ethyl 2-oxo-2,3,4,5-tetrahydro- $1 H$-benzo[ $b]$ azepine-3-carboxylate (2), but the overall efficiency suffered due to the modest yield of the initial transformation (Figure 1). ${ }^{6}$ Beyond this application, the possible addition of amines to these systems could

\footnotetext{
* Corresponding author. Tel.: +1 405744 5952; fax: +1 4057446007

E-mail address: rab@okstate.edu (R.A. Bunce).
}

have potential for the preparation of $\mathrm{CDC} 25$ phosphatase inhibitor analogues, such as $\mathbf{3}$, for the treatment of cancer. ${ }^{7,8}$ The current project sought to improve this transformation, and thus, render these targets more accessible.<smiles>CCOC(=O)C(CCc1ccccc1[N+](=O)[O-])C(=O)OCC</smiles>

Figure 1. Structures accessible by additions to vinylarenes.

Over the past few years, our efforts have focused on the development of atom-economical, $, 9,10$ cost-efficient, and transition metal-free methods for the synthesis of a wide variety of biologically active structural motifs including benzazepines, $^{6}$ dihydroquinolinones, ${ }^{11}$ tetrahydroquinolinones, ${ }^{12}$ 1,3,4-oxadiazoles, ${ }^{13}$ and pyrazoloquinolinones $^{14}$ among others. ${ }^{12}$ Hence, we sought to develop an efficient route for nucleophilic addition of active methylene compounds as well as amines to electron deficient vinylarenes as a route to heterocycle precursors. Nucleophiles do not normally react with styrene double bonds. However, when electronwithdrawing groups are present at $\mathrm{C} 2$ or $\mathrm{C} 4$ of the aromatic ring, the terminal vinyl carbon exhibits significant electrophilic character; similar groups at $\mathrm{C} 3$ do not activate the side chain $\pi$ bond. We took advantage of this phenomenon and explored the addition of diethyl malonate anion, generated using 1,8-diazabicyclo[5.4.0]undec-7-ene 
(DBU), to 4-nitrostyrene in DMF. Under these conditions, the reaction proceeded in moderate yield, and thus, we endeavored to optimize the conditions and expand the process.

Initial efforts evaluated various protic and aprotic solvents for the side chain addition (Table 1) and revealed that refluxing $\mathrm{MeCN}$ provided the best results. Reactions in DMF and DMSO at $60{ }^{\circ} \mathrm{C}$ proceeded faster, but these solvents proved more difficult to remove from the product. Other media such as EtOH and THF at their respective boiling points slowed the process and afforded lower yields.

Table 1. Solvent optimization for addition to polarized vinylarenes

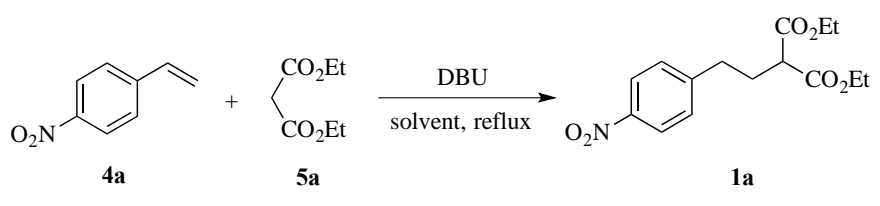

\begin{tabular}{cccc}
\hline Entry & Solvent / T $\left({ }^{\circ} \mathbf{C}\right)$ & Time (h) & Yield (\%) \\
\hline 1 & DMF / 60 & 2 & 56 \\
2 & MeCN / 82 & 4 & 93 \\
3 & $\mathrm{DMSO} / 60$ & 2 & 48 \\
4 & $\mathrm{EtOH} / 78$ & 18 & 25 \\
5 & $\mathrm{THF} / 67$ & 10 & 62 \\
\hline
\end{tabular}

${ }^{\mathrm{a}}$ Reactions were monitored by TLC and subjected to aqueous work-up to give the isolated yields reported.

Other potential bases for the reaction were also examined. Apart from DBU, tetramethylguanidine (TMG), 4-dimethylaminopyridine (DMAP), imidazole, 1,4-diazabicyclo[2.2.2]octane (DABCO), sodium hydride $(\mathrm{NaH})$ and potassium tert-butoxide $(t$-BuOK) were screened. These experiments confirmed that DBU was the base of choice for this transformation. Additionally, the highest yields were obtained using 1.0 equiv. of DBU relative to the vinylarene (Table 2).

Table 2. Optimization of base for addition to polarized vinylarenes

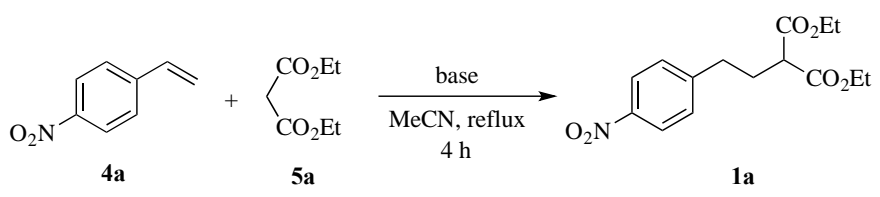

\begin{tabular}{cccc}
\hline Entry & Base & $\begin{array}{c}\text { Equiv } \\
\text { (rel to vinylarene) }\end{array}$ & Yield (\%) \\
\hline 1 & TMG & 1.0 & 36 \\
2 & DMAP & 1.0 & 28 \\
3 & imidazole & 1.0 & 45 \\
4 & DBU & 1.0 & 93 \\
5 & DABCO & 1.0 & 80 \\
6 & NaH & 1.0 & 65 \\
7 & $t$-BuOK & 1.0 & 23 \\
8 & DBU & 0.2 & 26 \\
9 & DBU & 0.5 & 59 \\
10 & DBU & 0.7 & 75 \\
\hline
\end{tabular}

Finally, the stoichiometry of the nucleophile was refined. While exploratory experiments utilized 2 equiv. of malonate, 1.5 equiv. also afforded good results. Further decreases, however, resulted in significantly diminished yields. Thus, the optimized conditions utilized 1 equiv. of the vinylarene acceptor, 1.5 equiv. of the nucleophile donor, and 1 equiv. of DBU.

With a standard protocol established, the scope of the reaction using various nucleophiles and substrates was investigated (Table 3 ). The optimized procedure worked well for 4-nitrostyrene (4a) with anions derived from diethyl malonate (5a) and diethyl methylmalonate $(\mathbf{5 b})$, giving excellent yields of products in 4-6 h. Substitution on the vinyl group was also examined using $\alpha$-methyl-4nitrostyrene (4b) and $\beta$-methyl-4-nitrostyrene (4c), and as expected, steric factors were found to be important in the reaction. Introduction of a methyl group $\alpha$ to the aromatic moiety (viz. $\mathbf{4 b}$ ) had little effect on the efficiency of addition, while placement of a methyl $\beta$ to the arene at the site of attack (viz. 4c) allowed addition by only unhindered nucleophiles such as 5a. Active methylene donors were also successfully added to 2-nitrostyrene (4d). In this series, the yield remained high for $\mathbf{5 a}$, but was lower for $\mathbf{5 b}$, presumably due to a steric hindrance created by the ortho nitro group. This steric interaction could impede approach of the nucleophile or distort the planarity of the system, which would decrease the elctrophilicity of the side chain double bond. Finally, modification of the substrates to include 4-cyano- and 4ethoxycarbonyl-substituted aromatic rings met with only limited success. In the case of 4-cyano-substituted acceptor $\mathbf{4 e}$, malonate nucleophiles added cleanly, but for the 4-ethoxycarbonyl-derived substrate $\mathbf{4 f}$, it was not possible to isolate acceptable yields of side chain adducts due to competitive attack at the ester carbonyl.

Table 3. Reactions of 4a-e with malonate donors $\mathbf{5 a - b}$
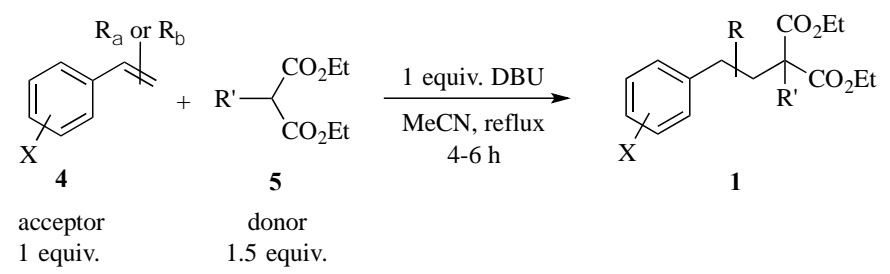

1 equiv. 1.5 equiv.

\begin{tabular}{cccc}
\hline Acceptor & Donor & Product & $\begin{array}{c}\text { Yield } \\
(\mathbf{\%})\end{array}$ \\
\hline $\mathbf{4 a}$ & $\mathbf{5 a}$ & $\mathbf{1 a}$ & 97 \\
$\left(\mathrm{X}=4-\mathrm{NO}_{2}, \mathrm{R}=\mathrm{H}\right)$ & $\left(\mathrm{R}^{\prime}=\mathrm{H}\right)$ & $\left(\mathrm{X}=4-\mathrm{NO}_{2}, \mathrm{R}, \mathrm{R}^{\prime}=\mathrm{H}\right)$ & \\
$\mathbf{4 a}$ & $\mathbf{5 b}$ & $\mathbf{1 b}$ & 93 \\
$\left(\mathrm{X}=4-\mathrm{NO}_{2}, \mathrm{R}=\mathrm{H}\right)$ & $\left(\mathrm{R}^{\prime}=\mathrm{Me}\right)$ & $\left(\mathrm{X}=4-\mathrm{NO}_{2}, \mathrm{R}=\mathrm{H}, \mathrm{R}^{\prime}=\mathrm{Me}\right)$ & \\
$\mathbf{4 b}$ & $\mathbf{5 a}$ & $\mathbf{1 c}$ & 87 \\
$\left(\mathrm{X}=4-\mathrm{NO}_{2}, \mathrm{R} \alpha=\mathrm{Me}\right)$ & $\left(\mathrm{R}^{\prime}=\mathrm{H}\right)$ & $\left(\mathrm{X}=4-\mathrm{NO}_{2}, \mathrm{R} \alpha=\mathrm{Me}, \mathrm{R}^{\prime}=\mathrm{H}\right)$ & \\
$\mathbf{4 b}$ & $\mathbf{5 b}$ & $\mathbf{1 d}$ & 85 \\
$\left(\mathrm{X}=4-\mathrm{NO}_{2}, \mathrm{R} \alpha=\mathrm{Me}\right)$ & $\left(\mathrm{R}^{\prime}=\mathrm{Me}\right)$ & $\left(\mathrm{X}=4-\mathrm{NO}_{2}, \mathrm{R} \alpha, \mathrm{R}^{\prime}=\mathrm{Me}\right)$ & \\
$\mathbf{4 c}$ & $\mathbf{5 a}$ & $\mathbf{1 e}$ & 50 \\
$\left(\mathrm{X}=4-\mathrm{NO}_{2}, \mathrm{R} \beta=\mathrm{Me}\right)$ & $\left(\mathrm{R}^{\prime}=\mathrm{H}\right)$ & $\left(\mathrm{X}=4-\mathrm{NO}_{2}, \mathrm{R} \beta=\mathrm{Me}, \mathrm{R}^{\prime}=\mathrm{H}\right)$ & \\
$\mathbf{4 d}$ & $\mathbf{5 a}$ & $\mathbf{1 f}$ & 94 \\
$\left(\mathrm{X}=2-\mathrm{NO}_{2}, \mathrm{R}=\mathrm{H}\right)$ & $\left(\mathrm{R}^{\prime}=\mathrm{H}\right)$ & $\left(\mathrm{X}=2-\mathrm{NO}_{2}, \mathrm{R}, \mathrm{R}^{\prime}=\mathrm{H}\right)$ & \\
$\mathbf{4 d}$ & $\mathbf{5 b}$ & $\mathbf{1 g}$ & 74 \\
$\left(\mathrm{X}=2-\mathrm{NO}_{2}, \mathrm{R}=\mathrm{H}\right)$ & $\left(\mathrm{R}^{\prime}=\mathrm{Me}\right)$ & $\left(\mathrm{X}=2-\mathrm{NO}_{2}, \mathrm{R}=\mathrm{H}, \mathrm{R}^{\prime}=\mathrm{Me}\right)$ & \\
$\mathbf{4 e}$ & $\mathbf{5 a}$ & $\mathbf{1 h}$ & 58 \\
$(\mathrm{X}=4-\mathrm{CN}, \mathrm{R}=\mathrm{H})$ & $\left(\mathrm{R}^{\prime}=\mathrm{H}\right)$ & $\left(\mathrm{X}=4-\mathrm{CN}, \mathrm{R}, \mathrm{R}^{\prime}=\mathrm{H}\right)$ & \\
$\mathbf{4 e}$ & $\mathbf{5 b}$ & $\mathbf{1 i}$ & 53 \\
$(\mathrm{X}=4-\mathrm{CN}, \mathrm{R}=\mathrm{H})$ & $\left(\mathrm{R}^{\prime}=\mathrm{Me}\right)$ & $\left(\mathrm{X}=4-\mathrm{CN}, \mathrm{R}=\mathrm{H}, \mathrm{R}^{\prime}=\mathrm{Me}\right)$ & \\
\hline & & &
\end{tabular}

The transformation was further extended to the addition of methyl 2-oxocyclopentanecarboxylate (6). The enolate of this relatively hindered $\beta$-ketoester reacted with $\mathbf{4 a}, \mathbf{4 b}, \mathbf{4 d}$, and $4 \mathbf{e}$ in MeCN (reflux, 4-6 h) to give 7a (81\%), 7b (82\%), 7d (80\%), and 7e $(51 \%)$, respectively (Table 4$)$. Notably, product $7 \mathbf{b}$, derived from addition of 6 to $4 b(R \alpha=M e)$, consisted of two diastereomers in a nearly 1:1 ratio. Separation by preparative TLC gave isomer A (39\%), an oil, and isomer B (43\%), a white solid. A crystal of isomer B was obtained for X-ray analysis by slow diffusion of pentane into an ether solution of the two diastereomers. Solution of the structure (Figure 2) showed isomer B to be racemic methyl 
Table 4. Reactions of $\mathbf{4 a}, \mathbf{b}, \mathbf{d}$ and $\mathbf{e}$ with cyclic $\beta$-ketoester 6
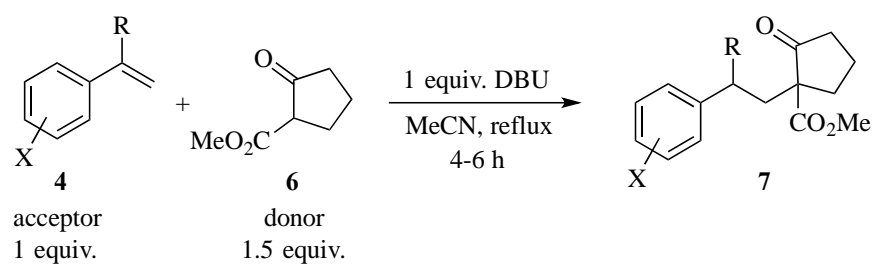

1 equiv.

1.5 equiv.

\begin{tabular}{ccc}
\hline Acceptor & Product & Yield (\%) \\
\hline $\mathbf{4 a}$ & $\mathbf{7 a}$ & 81 \\
$\left(\mathrm{X}=4-\mathrm{NO}_{2}, \mathrm{R}=\mathrm{H}\right)$ & $\left(\mathrm{X}=4-\mathrm{NO}_{2}, \mathrm{R}=\mathrm{H}\right)$ & $82^{\mathrm{a}}$ \\
$\mathbf{4 b}$ & $\mathbf{7 b}$ & \\
$\left(\mathrm{X}=4-\mathrm{NO}_{2}, \mathrm{R} \alpha=\mathrm{Me}\right)$ & $\left(\mathrm{X}=4-\mathrm{NO}_{2}, \mathrm{R} \alpha=\mathrm{Me}\right)$ & 80 \\
$\mathbf{4 d}$ & $\mathbf{7 d}$ & \\
$\left(\mathrm{X}=2-\mathrm{NO}_{2}, \mathrm{R}=\mathrm{H}\right)$ & $\left(\mathrm{X}=2-\mathrm{NO}_{2}, \mathrm{R}=\mathrm{H}\right)$ & 51 \\
$\mathbf{4 e}$ & $\mathbf{7 e}$ & \\
$(\mathrm{X}=4-\mathrm{CN}, \mathrm{R}=\mathrm{H})$ & $(\mathrm{X}=4-\mathrm{CN}, \mathrm{R}=\mathrm{H})$ & \\
\hline
\end{tabular}

${ }^{\text {a }}$ Isolated as a mixture of diastereomers with the following relative configurations: $( \pm)-R, S=39 \%$; $( \pm)-R, R=43 \%$.

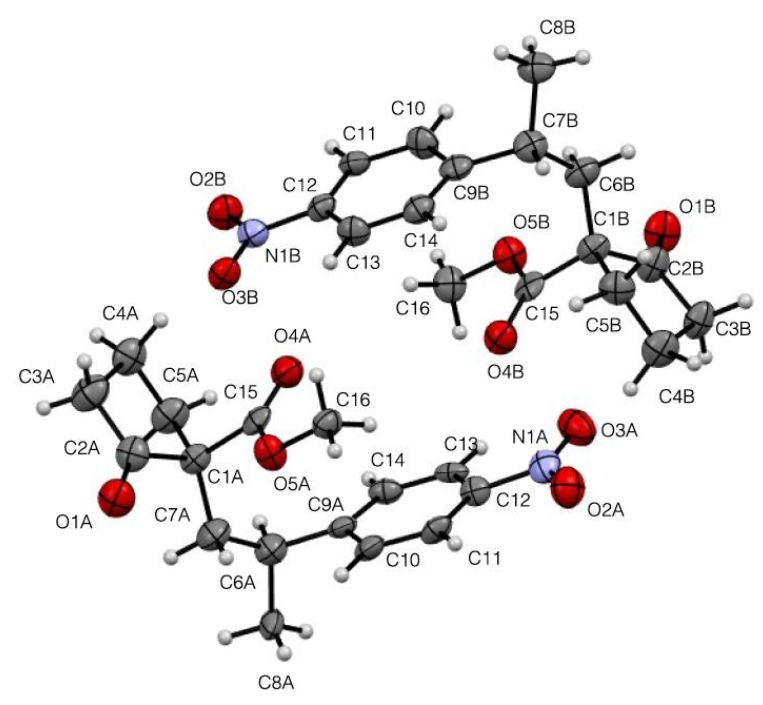

Figure 2. X-ray structure of $( \pm)-(R, R)-7 \mathbf{b}(\mathrm{CCDC} 1454607)$. Note: The unit cell for $( \pm)-(R, R)-7 \mathbf{b}$ contained one molecule of the $R, R$ (top) and one molecule of the $S, S$ enantiomer (bottom).

$(R, R)$-2-oxo-1-[2-(4-nitrophenyl)propyl]cyclopentanecarboxylate $[( \pm)-(R, R)-7 \mathbf{b}]$, allowing assignment of isomer $\mathrm{A}$ as $( \pm)-(R, S)-7 \mathbf{b}$.

Further experiments explored the feasibility of hydroaminating polarized alkenes 4a-f with morpholine $(\mathbf{8})$, piperidine (9) and benzylamine (10). Using 1.5 equiv. of the amines, several of these additions also proceeded in high yield, but longer reaction times (12$18 \mathrm{~h}$ ) were required relative to those involving carbon nucleophiles. Control experiments, with and without added base, established that DBU was also required for good conversions in these reactions. Additions of 8-10 to nitrostyrenes $4 \mathbf{a}$ and $4 d$ gave 11-13a and 1113d, respectively, in 78-95\% yields (Table 5). On the other hand, these same robust conditions promoted rapid polymerization and/or degradation of the 4-cyano- and 4-ethoxycarbonyl substrates $\mathbf{4 e}$ and 4f. For the side chain substituted acceptors, addition to $\alpha$-methyl-4nitrostyrene (4b) gave adducts $\mathbf{1 1 - 1 3 b}$ in $77-86 \%$ yields (Table 5), while $\beta$-methyl-4-nitrostyrene (4c) failed to react, presumably due to steric congestion at the site of attack. In the absence of activating groups, hydroamination processes normally require transition metal catalysis. $^{15-23}$
Table 5. Reactions of $4 a, b$ and $d$ with amine donors 8-10
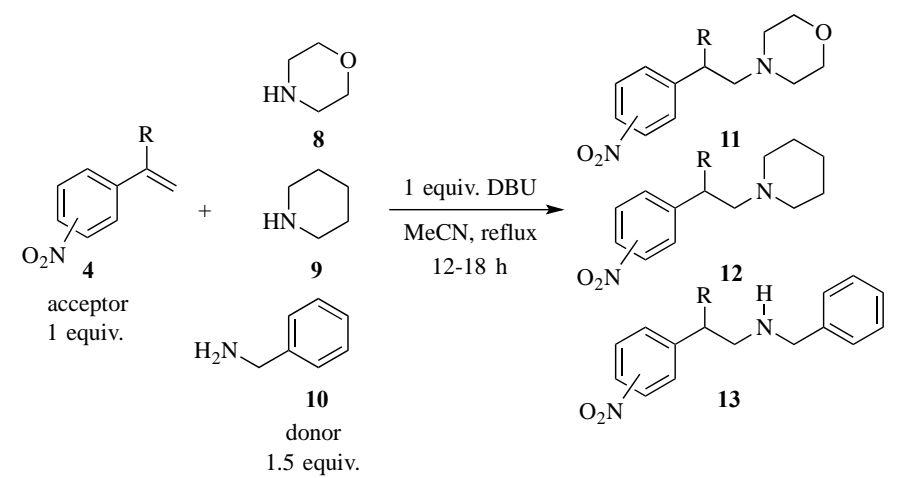

\begin{tabular}{|c|c|c|c|}
\hline Acceptor & Donor & Product & Yield (\%) \\
\hline $\begin{array}{c}\mathbf{4 a} \\
\left(4-\mathrm{NO}_{2}, \mathrm{R}=\mathrm{H}\right)\end{array}$ & 8 & $\begin{array}{c}11 \mathbf{a} \\
\left(4-\mathrm{NO}_{2}, \mathrm{R}=\mathrm{H}\right)\end{array}$ & 95 \\
\hline $\begin{array}{c}\mathbf{4 a} \\
\left(4-\mathrm{NO}_{2}, \mathrm{R}=\mathrm{H}\right)\end{array}$ & 9 & $\begin{array}{c}\text { 12a } \\
\left(4-\mathrm{NO}_{2}, \mathrm{R}=\mathrm{H}\right)\end{array}$ & 93 \\
\hline $\begin{array}{c}\mathbf{4 a} \\
\left(4-\mathrm{NO}_{2}, \mathrm{R}=\mathrm{H}\right)\end{array}$ & 10 & $\begin{array}{c}\text { 13a } \\
\left(4-\mathrm{NO}_{2}, \mathrm{R}=\mathrm{H}\right)\end{array}$ & 82 \\
\hline $\begin{array}{c}\mathbf{4 b} \\
\left(4-\mathrm{NO}_{2}, \mathrm{R}=\mathrm{Me}\right)\end{array}$ & 8 & $\begin{array}{c}\mathbf{1 1 b} \\
\left(4-\mathrm{NO}_{2}, \mathrm{R}=\mathrm{Me}\right)\end{array}$ & 86 \\
\hline $\begin{array}{c}\mathbf{4 b} \\
\left(4-\mathrm{NO}_{2}, \mathrm{R}=\mathrm{Me}\right)\end{array}$ & 9 & $\begin{array}{c}\mathbf{1 2 b} \\
\left(4-\mathrm{NO}_{2}, \mathrm{R}=\mathrm{Me}\right)\end{array}$ & 84 \\
\hline $\begin{array}{c}\mathbf{4 b} \\
\left(4-\mathrm{NO}_{2}, \mathrm{R}=\mathrm{Me}\right)\end{array}$ & 10 & $\begin{array}{c}\text { 13b } \\
\left(4-\mathrm{NO}_{2}, \mathrm{R}=\mathrm{Me}\right)\end{array}$ & 77 \\
\hline $\begin{array}{c}\mathbf{4 d} \\
\left(2-\mathrm{NO}_{2}, \mathrm{R}=\mathrm{H}\right)\end{array}$ & 8 & $\begin{array}{c}\text { 11d } \\
\left(2-\mathrm{NO}_{2}, \mathrm{R}=\mathrm{H}\right)\end{array}$ & 85 \\
\hline $\begin{array}{c}\mathbf{4 d} \\
\left(2-\mathrm{NO}_{2}, \mathrm{R}=\mathrm{H}\right)\end{array}$ & 9 & $\begin{array}{c}\text { 12d } \\
\left(2-\mathrm{NO}_{2}, \mathrm{R}=\mathrm{H}\right)\end{array}$ & 88 \\
\hline $\begin{array}{c}\mathbf{4 d} \\
\left(2-\mathrm{NO}_{2}, \mathrm{R}=\mathrm{H}\right)\end{array}$ & 10 & $\begin{array}{c}\text { 13d } \\
\left(2-\mathrm{NO}_{2}, \mathrm{R}=\mathrm{H}\right)\end{array}$ & 78 \\
\hline
\end{tabular}

The presumed mechanism for the reaction of $4 \mathbf{a}$ with $\mathbf{5 a}$ to give 1a is depicted in Figure 3. Deprotonation of 5a using DBU would generate DBU- $\mathrm{H}^{+}$and carbanion 14. In the presence of $4 \mathbf{a}, 14$ would add to the side chain double bond to generate adduct $\mathbf{1 5}$. Intermediate $\mathbf{1 5}$ is stabilized in much the same manner as a Meisenheimer complex, but does not have a leaving group at the site of attack, which would allow regeneration of the side chain double bond. Abstraction of the proton from DBU-H $\mathrm{H}^{+}$(or excess $\mathbf{4 a}$ ) by $\mathbf{1 5}$ would then deliver the required single addition product 1a. When the current reaction was performed using 0.2 equiv. of DBU in DMF at $60{ }^{\circ} \mathrm{C}$, a very poor yield of $1 \mathbf{a}$ was obtained and more of the double addition product $\mathbf{1 7}$ was isolated. A likely explanation for this observation is that intramolecular proton transfer from the active methylene site to the benzylic anion in $\mathbf{1 5}$ is faster than intermolecular proton abstraction from the dilute $\mathrm{DBU}-\mathrm{H}^{+}$. This would generate 16, which would then add a second molecule of $\mathbf{4 a}$ and protonate to form 17. Experiments to optimize the stoichiometry of DBU indicated that a full equivalent of this base relative to the vinylarene gave the highest conversion to the monoadduct. Though intramolecular proton transfer should still be faster, the presence of higher concentrations of DBU- $\mathrm{H}^{+}$along with excess $4 \mathbf{a}$ would make more protons available from intermolecular sources to stop the reaction at the single addition stage. Of course, the intramolecular proton transfer and double addition would not be an issue for reactions involving alkylated malonates such as $\mathbf{5 b}$.

In conclusion, nucleophilic additions of enolates and amines to electron deficient vinylarenes substituted in the ortho or para positions by nitro, cyano, and ethoxycarbonyl have been explored and optimized. This reaction proceeded cleanly for nitro compounds $\mathbf{4 a}$ and $\mathbf{4 d}$ with malonates $\mathbf{5 a}$ and $\mathbf{5 b}$, giving better yields than earlier 


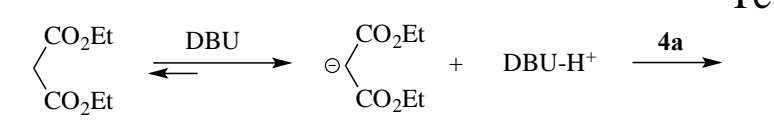

$5 \mathbf{a}$

14

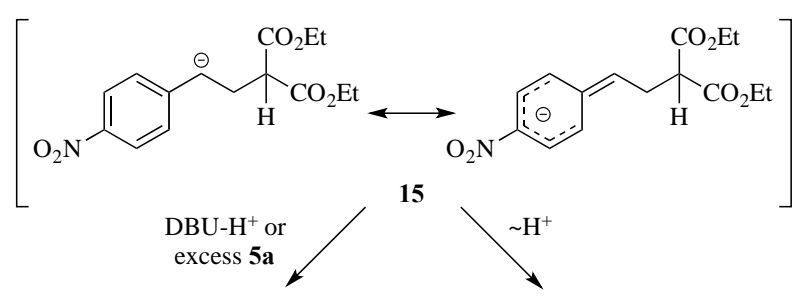<smiles>CCOC(=O)C(CCc1ccc([N+](=O)[O-])cc1)C(=O)OCCc1ccc([N+](=O)[O-])cc1</smiles>

$1 \mathbf{a}$<smiles>CCOC(=O)C(CCc1ccc([18F])cc1)(CCc1ccc([N+](=O)[O-])cc1)C(=O)OCC</smiles>

17

Figure 3. Presumed mechanism for additions to electron-deficient vinylarenes.

reports without the need for added metal catalysts. The reaction is operationally simple and proceeds to give high yields in refluxing $\mathrm{MeCN}$ after 4-6 h. Additions of the hindered $\beta$-ketoester 6 were also successful. For cyano compound $\mathbf{4 e}$, only the malonate and ketoester nucleophiles afforded the desired adducts, albeit in lower yields than those observed for the nitro compounds. The ethoxycarbonylsubstituted substrate $\mathbf{4 f}$ proved too labile under the current reaction protocol, giving reactions at the ester carbonyl along with polymer formation. Addition to the nitrostyrene substrate $\mathbf{4 b}$ with a methyl group at the $\alpha$ side chain position was also successful, but substrate 4c with a $\beta$ methyl group was too hindered for additions beyond unsubstituted malonate. The hydroamination procedure permitted the addition of primary and secondary amines 8-10 to nitrostyrenes 4a, 4b and 4d without added catalysts in MeCN at reflux for 12-18 h. Other acceptors incorporating 4-cyano and 4-ethoxycarbonyl underwent polymerization or degradation upon attempted addition of amines. The targets generated have high potential value for the synthesis of building blocks to assemble the backbone of several families of drug candidates.

\section{Acknowledgments}

The authors are grateful to NSF (BIR-9512269), the Oklahoma State Regents for Higher Education, the W. M. Keck Foundation, and Conoco, Inc. for funding to establish the Oklahoma Statewide Shared NMR Laboratory. The College of Arts and Sciences at OSU is also acknowledged for funds to purchase a new $400 \mathrm{MHz}$ NMR for this facility. We wish to further thank the NSF (CHE-0130835) and the University of Oklahoma for funding to establish the OU Chemical Crystallography Laboratory. Finally, we are pleased to acknowledge
Dr. Douglas R. Powell for his skill in acquiring the X-ray crystal structure.

\section{Supplemental information}

Supplementary information associated with this article (experimental procedures, spectral data for the products, and details of the X-ray structure determination for CCDC 1454607) can be found, in the online version, at http://dx.doi.org/10.1016/j.tetlet

\section{References and notes}

1. Bergmann, E. D. G., D.; Pappo, R. In Organic Reactions; Krieger Publishing, Malabar, FL, 1959; Vol. 10, pp 179-555.

2. Kürti, L.; Czakó, B. Strategic Applications of Named Reactions in Organic Synthesis; Elsevier Academic Press, New York, NY, 2005, pp 286-287.

3. Bunnett, J. F.; Zahler, R. E. Chem. Rev. 1951, 49, 273-412.

4. Carey, F. A.; Sundberg, R. J. Advanced Organic Chemistry, Part B. Reactions and Synthesis; Springer, New York, NY, 2007, pp 1035-1039.

5. Dale, W. J.; Strobel, C. W. J. Am. Chem. Soc. 1954, 76, 61726174.

6. Nammalwar, B.; Bunce, R. A.; Hiett, J. T. Org. Prep. Proced. Int. 2015, 47, 338-355.

7. Contour-Galcéra, M.-O.; Lavergne, O.; Brezak, M.-C.; Ducommun, B.; Prévost, G. Bioorg. Med. Chem. Lett. 2004, 14, 5809-5812.

8. Prevost, G.; Brezak Pannetier, M.-C.; Galcera Contour, M.-O.; Thurieau, C.; Goubin-Grammatica, F.; Ducommun, B.; Lanco, C. International Patent WO 2002009686 A2, 2002; Chem. Abstr. 2002, 136, 167182..

9 Trost, B. M. Science 1991, 254, 1471-1477.

10. Trost, B. M. Angew. Chem., Int. Ed. 1995, 34, 259-281.

11. Bunce, R. A.; Nago, T.; Abuskhuna, S. J. Heterocycl. Chem. 2015, 52, 1143-1149.

12. Nammalwar, B.; Bunce, R. Molecules 2013, 19, 204-232.

13. Gnanasekaran, K. K.; Nammalwar, B.; Murie, M.; Bunce, R. A. Tetrahedron Lett. 2014, 55, 6776-6778.

14. Gnanasekaran, K. K.; Muddala, N. P.; Bunce, R. A. Tetrahedron Lett. 2015, 56, 1367-1369.

15. Müller, T. E.; Beller, M. Chem. Rev. 1998, 98, 675-704.

16. Beller, M.; Trauthwein, H.; Eichberger, M.; Breindl, C.; Herwig, J.; Muller, T. E.; Thiel, O. R. Chem-Eur. J. 1999, 5, 1306-1319.

17. Seayad, J.; Tillack, A.; Hartung, C. G.; Beller, M. Adv. Synth. Catal. 2002, 344, 795-813.

18. Utsunomiya, M.; Kuwano, R.; Kawatsura, M.; Hartwig, J. F. J. Am. Chem. Soc. 2003, 125, 5608-5609.

19. Utsunomiya, M.; Hartwig, J. F. J. Am. Chem. Soc. 2004, 126, 2702-2703.

20. Hong, S.; Marks, T. J. Acc. Chem. Res. 2004, 37, 673-686.

21. Beller, M.; Seayad, J.; Tillack, A.; Jiao, H. Angew. Chem., Int. Ed. 2004, 43, 3368-3398.

22. Kaspar, L. T.; Fingerhut, B.; Ackermann, L. Angew. Chem., Int. Ed. 2005, 44, 5972-5974.

23. Munro-Leighton, C.; Delp, S. A.; Alsop, N. M.; Blue, E. D.; Gunnoe, T. B. Chem. Commun. 2008, 111-113. 
Graphical Abstract

Nucleophilic Additions to Polarized Vinylarenes

Krishna Kumar Gnanasekaran, Junghak Yoon and

Leave this area blank for abstract info.

Richard A. Bunce*

Department of Chemistry, Oklahoma State University, Stillwater, OK 74078-3071, USA

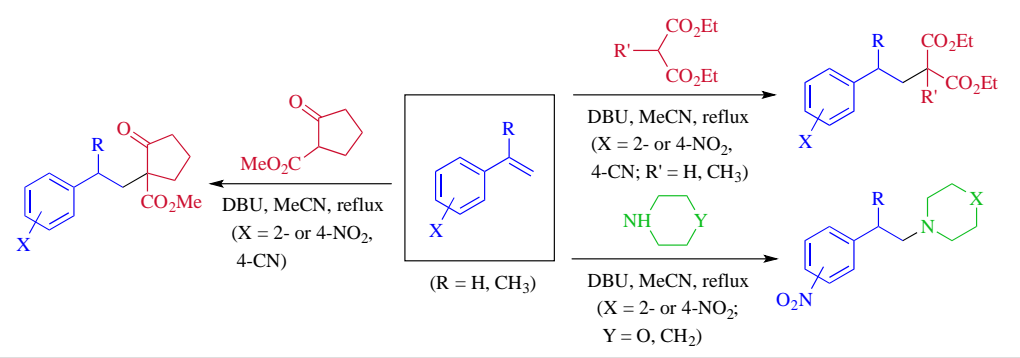

